\title{
NÍVEIS DE MATURIDADE VOCACIONAL DE ALUNOS DE 14 A 18 ANOS DO RIO GRANDE DO SUL
}

\author{
Marcos Alencar Abaide Balbinotti \\ Bernard Tétreau*
}

\begin{abstract}
RESUMO. Maturidade vocacional é a capacidade de enfrentar tarefas de desenvolvimento com as quais se é confrontado; como conseqüência do próprio desenvolvimento social e biológico e das necessidades da sociedade em relação às pessoas que alcançam esse estado de desenvolvimento. O estudo explora diferenças nos níveis de maturidade vocacional segundo sexo, idade, ano do ensino médio e tipo de escola. Uma amostra de 860 estudantes do ensino médio, de ambos os sexos e idades de 14 a 18 anos, das redes pública e privada, respondeu o Questionário de Educação à Carreira (QEC). Resultados indicam diferenças significativas $(p<0,05)$ nas respostas quando controladas as variáveis: sexo, tipo de escola e ano do ensino médio. $\mathrm{O}$ fato de pertencer a uma das 5 idades em estudo não determina maturidade vocacional estatisticamente maior. Uma das principais conclusões é que os adolescentes da rede pública poderão se ver forçados a aceitar oportunidades profissionais que aparecem, forçando uma "maturidade vocacional prematura".
\end{abstract}

Palavras-chave: maturidade vocacional, adolescência, desenvolvimento de carreira.

\section{LEVELS OF VOCATIONAL MATURITY IN HIGH SCHOOL STUDENTS, AGED 14 TO 18, IN RIO GRANDE DO SUL}

\begin{abstract}
Vocational maturity is the capacity to face the development tasks, which one is confronted with as a consequence of one's own social-biological development and society's expectations for the individuals who reach such a condition of development. Differences regarding the levels of vocational maturity are explored in this study, according to sex, age, level of high school education and type of school attended. A sample of 860 high school students - from14 to 18 years old, male and female, attending public and private schools - answered the Questionnaire related to Career Education (QCE). The results show significant differences $(p<0.05)$ when variables such as sex, type of school and level of high school education are controlled. Age does not determine a statistically higher vocational maturity. As main conclusion it is pointed out, that adolescents from public schools may be forced to accept the emerging professional opportunities, thus facing a "premature vocational maturity".
\end{abstract}

Key words: Vocational maturity, adolescence, career development.

\section{NIVELES DE MADUREZ VOCACIONAL DE ALUMNOS DE 14 A 18 AÑOS DE RIO GRANDE DO SUL}

\begin{abstract}
RESUMEN. Madurez vocacional es la capacidad de enfrentarse tareas de desarrollo con las cuales se es confrontado; como consecuencia del propio desarrollo social y biológico y de las necesidades de la sociedad en relación con las personas que alcanzan ese estado de desarrollo. El estudio explora diferencias en los niveles de madurez vocacional según el sexo, edad, año de Enseñanza Media y tipo de escuela. Una muestra de 860 estudiantes de Enseñanza Media, de ambos sexos y edades de 14 a 18 años, de las redes pública y privada, respondió el Cuestionario de Educación a la Carrera (QEC). Resultados indican diferencias significativas $(p<0,05)$ en las respuestas cuando controladas las variables: sexo, tipo de escuela y año de Enseñanza Media. El hecho de pertenecer a una de las 5 edades en estudio no determina madurez vocacional estadísticamente mayor. Una de las principales conclusiones es que los adolescentes de red pública podrán verse forzados a aceptar oportunidades profesionales que aparecen, obligando una "madurez vocacional prematura".
\end{abstract}

Palabras-clave: madurez vocacional, adolescencia, desarrollo de carrera.

* Ph.D. Professor Adjunto da Universidade do Vale do Rio dos Sinos-UNISINOS, Brasil. Professor Colaborador na Université de Sherbrooke, USherbrooke, Canadá

\# Ph.D. Professor Titular e Honorário da Université de Montréal-UdeM, Canadá. 
Este artigo apresenta resultados de dados colhidos em oito escolas (de três cidades) gaúchas e explora a ocorrência de possíveis diferenças significativas ou semelhanças estatísticas nos níveis de maturidade vocacional de alunos do ensino médio, dentro do contexto da Teoria Geral da Escolha e do Desenvolvimento Profissional (TGEDP) de Super, conforme as variáveis de controle: sexo, idade, ano do ensino médio e, finalmente, tipo de escola (se pública ou privada). Para melhor responder a este objetivo, apresentam-se, inicialmente, aspectos referentes ao plano teórico relativo à maturidade profissional e, em seguida, aqueles referentes ao plano empírico (também relativo a este mesmo conceito). Finalmente, após a apresentação do método (procedimentos, sujeitos e instrumentos), são apresentados os resultados conforme os princípios métricos norteadores comumente aceitos na literatura especializada. As conclusões têm origem neste processo.

\section{MATURIDADE VOCACIONAL NO CONTEXTO DA TEORIA DE DONALD E. SUPER}

A Teoria Geral da Escolha e do Desenvolvimento Profissional (TGEDP) integra quatro modelos básicos que buscam explicar o comportamento vocacional de um indivíduo, a saber: Modelo da Perspectiva Diferencial (MPD), Modelo Socioeconômico e Ambiental (MSEA), Modelo Desenvolvimentista (MD), e, finalmente, Modelo Fenomenológico (MF). Uma descrição mais detalhada e objetiva destes modelos poderá ser consultada em uma recente publicação nacional (Balbinotti, 2003), com informações compiladas dos originais do próprio autor (Super, 1953, 1957, 1972, 1980, 1985a, 1985b, 1990; Super, Sverko \& Super, 1995); mas uma síntese pode ser observada na Tabela 1a, apresentada abaixo.

Tabela 1a. Modelos que Buscam Explicar o Comportamento Vocacional de um Indivíduo

\begin{tabular}{|c|c|c|}
\hline Modelo & Sigla & Observações pertinentes aos Modelos \\
\hline $\begin{array}{l}\text { Modelo da perspectiva } \\
\text { diferencial }\end{array}$ & MPD & $\begin{array}{l}\text { Relacionado com as concepções teóricas de Parsons (1909), apóia-se numa psicologia diferencial dos } \\
\text { indivíduos e das ocupações; é o modelo tradicional, aquele que Holland (1959, 1997) representa em sua } \\
\text { forma contemporânea e segundo o qual se busca assegurar o homem certo no lugar certo a partir de } \\
\text { uma análise das características do indivíduo e da profissão considerada. }\end{array}$ \\
\hline $\begin{array}{l}\text { Modelo socioeconômico e } \\
\text { ambiental }\end{array}$ & MSEA & $\begin{array}{l}\text { Aquele da influência dos fatores socioeconômicos e ambientais (família, escola, comunidade, grupo de } \\
\text { pares, sociedade, economia, mercado de trabalho, políticas sociais e experiências profissionais). Por } \\
\text { exemplo, para Super (1957), a família contribui para o desenvolvimento de necessidades e valores } \\
\text { fornecendo à criança (adolescente) a possibilidade de adquirir informações e desenvolver habilidades que } \\
\text { poderão ter uma importante influência no momento da tomada de decisão profissional por parte dos } \\
\text { jovens. }\end{array}$ \\
\hline Modelo desenvolvimentista & MD & $\begin{array}{l}\text { Este modelo propõe que o desenvolvimento profissional é um processo contínuo desde a infância até a } \\
\text { velhice. É, ao mesmo tempo, ordenado (previsível) e dinâmico (no sentido de que ele resulta da interação } \\
\text { entre as características do indivíduo e as demandas da cultura). No decorrer deste processo, o indivíduo } \\
\text { deve cumprir certo número de tarefas de desenvolvimento, e a maneira pela qual ele as cumpre revela sua } \\
\text { maturidade vocacional. Dentro desta ótica, um indivíduo é maduro na medida em que esteja pronto } \\
\text { para tomar as decisões e para assumir os comportamentos característicos de seu estado de } \\
\text { desenvolvimento (Super, 1990; Super, Savickas \& Super, 1996) (ver Tabela 1). }\end{array}$ \\
\hline Modelo fenomenológico & MF & $\begin{array}{l}\text { Também conhecido como Modelo do Autoconceito (MA) - precisamente, sistemas de autoconceitos. } \\
\text { Segundo Super (1990), o autoconceito, e mais precisamente o autoconceito profissional (ou vocacional), } \\
\text { tem um papel organizacional maior como guia do comportamento do indivíduo através dos estados e } \\
\text { subestados do desenvolvimento vocacional. Desta forma, ele escreveu: "(..) formulando uma preferência } \\
\text { vocacional, o indivíduo exprime uma idéia do tipo de pessoa que ele pensa ser; escolhendo uma } \\
\text { profissão, ele atualiza seu autoconceito; progredindo numa carreira, ele se atualiza" (Super, 1963a, p. 4). }\end{array}$ \\
\hline
\end{tabular}

Como se pode constatar, é no terceirov modelo desta grande e integradora teoria que se agrega o conceito maturidade vocacional. Super (1955) inicialmente focalizou esse conceito quando escreveu, pela primeira vez, a propósito das dimensões e medidas da maturidade vocacional. Ele queria, assim, estabelecer os critérios para descrever e avaliar os estados e os subestados do desenvolvimento da carreira de estudantes com diferentes idades e níveis de estudo, tanto quanto as tarefas do desenvolvimento com as quais eles estavam confrontados e, desta maneira, seu nível de preparação para resolver estas tarefas para, assim, escolher uma carreira. Mais tarde (Super, 1963b), ele tentou definir esta noção de uma maneira operacional, escrevendo de forma ainda mais detalhada as tarefas de desenvolvimento, assim como os atributos e comportamentos característicos da adolescência e da vida adulta, como podemos encontrar na Tabela 1b. Em seus trabalhos mais recentes (Super, 1990; Super, Savickas e Super, 1996), a maturidade vocacional é definida como a capacidade do indivíduo para enfrentar as tarefas de 
desenvolvimento com as quais ele é confrontado, entre as quais se incluem, por um lado, as tarefas de seu desenvolvimento social e biológico, e por outro, as necessidades da sociedade em relação às outras pessoas que alcançam este estado de desenvolvimento.

Tabela 1b. Estados, Subestados e Tarefas de Desenvolvimento Associadas

\begin{tabular}{|c|c|c|}
\hline Estados (idades) & Subestados & Tarefas de desenvolvimento \\
\hline $\begin{array}{l}\text { Crescimento } \\
(0-14 \text { anos })\end{array}$ & $\begin{array}{l}\text { - Fantasista/curiosidade } \\
\text { - Desenvolvimento dos interesses e aptidões }\end{array}$ & $\begin{array}{l}\text { - Aprendizagem das técnicas gerais de adaptação } \\
\text { - Formação de um autoconceito vocacional }\end{array}$ \\
\hline $\begin{array}{l}\text { Exploração } \\
(14-25 \text { anos })\end{array}$ & $\begin{array}{l}\text { - Provisório/planificação } \\
\text { - Transição } \\
\text { - Tentativa }\end{array}$ & $\begin{array}{l}\text { - Cristalização de uma preferência profissional } \\
\text { - Especificação de uma preferência profissional } \\
\text { - Atualização de uma preferência profissional }\end{array}$ \\
\hline $\begin{array}{l}\text { Estabelecimento } \\
(21-45 \text { anos })\end{array}$ & $\begin{array}{l}\text { - Estabelecimento } \\
\text { - Avanço }\end{array}$ & $\begin{array}{l}\text { - Estabilização em uma profissão } \\
\text { - Consolidação do status e avanço profissional }\end{array}$ \\
\hline $\begin{array}{l}\text { Manutenção } \\
(40-65 \text { anos })\end{array}$ & - Adaptação e preservação do Autoconceito & - Manter posição, atualizar-se e inovar-se \\
\hline $\begin{array}{l}\text { Desengajamento } \\
\text { (mais de } 65 \text { anos) }\end{array}$ & - Adaptação a um novo self e ao processo de aposentadoria & $\begin{array}{l}\text { - Desaceleração, planificação da aposentadoria e da vida } \\
\text { de aposentado }\end{array}$ \\
\hline
\end{tabular}

\section{ESTUDO CLÁSSICO DE VERIFICAÇÃO EMPÍRICA DA MATURIDADE VOCACIONAL}

Donald E. Super e seus colaboradores, no Teachers College da Universidade de Columbia, e mesmo diversos outros pesquisadores, já tentaram colocar à prova sua teoria de várias maneiras; mas a mais conhecida é, sem dúvida, aquela que representa seu estudo de padrões de carreira (Career Pattern Study - CPS), de 1985. Precisamente, trata-se de um estudo longitudinal que se iniciou em 1951, com jovens de $9^{\circ}$ ano escolar (entre 14 e 15 anos) e durou os 25 anos seguintes, isto é, até o momento em que a maior parte dos sujeitos $(70 \%$ deles, precisamente) estava estabilizada, em padrões de carreira. Este estudo permitiu estabelecer as relações entre a maneira como os sujeitos passavam pelas tarefas de desenvolvimento profissional correspondentes ao estágio de exploração na adolescência (cristalização, 14-18 anos) e o status de seus comportamentos vocacionais no estágio de estabelecimento (estabilização, 21 a 30 anos e 30 a 45 anos em uma profissão), por comparação com as predições deste mesmo status a partir das medidas convencionais das características dos sujeitos (inteligência, rendimento escolar, nível socioeconômico e autoconceito vocacional).

Com o estudo do CPS, Super (1985b) concluiu que as medidas de maturidade vocacional no $12^{\circ}$ ano escolar (graus de planificação, de exploração e de preparação a tomar as decisões que requerem as necessidades sociais e as circunstâncias) são mais potentes como preditores de variáveis critérios em 25 anos (status ocupacional esperado, avanço ocupacional, satisfação ocupacional, progresso e satisfação na carreira) do que as medidas convencionais (inteligência, status socioeconômico, sucesso escolar, etc.) e do autoconceito (precisamente duas metadimensões: harmonia e idiossincrasia). Como não se poderia duvidar, a utilização combinada de dois tipos de medida melhora as predições, mas é conveniente remarcar que, já no $9^{\circ}$ ano escolar, certas características e comportamentos têm uma relação com o desenvolvimento de carreira e a atualização de uma preferência profissional 10 anos mais tarde, notadamente o status ocupacional esperado e o progresso na carreira.

\section{MEDIDAS ATUAIS DE MATURIDADE VOCACIONAL NO CONTEXTO DA TEORIA DE DONALD E. SUPER}

Foi neste furor que se publicou, em 1972, a primeira versão do Career Development Inventory (CDI) (Forrest e Thompson, 1974). Concebida para ser utilizada, basicamente, com adolescentes, esta primeira versão do CDI foi, em seguida, modificada, respondendo assim a melhores qualidades métricas e dando lugar às versões do CDI-A (para jovens adultos) e do Adult Career Concerns Inventory (ACCI) (Super, Thompson e Lindeman, 1988). Tevese a oportunidade de verificar que estes instrumentos foram traduzidos ou adaptados em amostras de adolescentes e adultos de diversos países (Espanha, Canadá, França, Áustria, África do Sul, Países Baixos, Portugal, Reino Unido e Austrália). Estes e outros instrumentos, quando inspirados na teoria de Super, foram elaborados para se poderem medir dimensões da maturidade vocacional. Faz-se referência precisamente ao Career Maturity Inventory (CMI) (Crites, 1978) e ao Questionário de Educação à 
Carreira (QEC) (Dupont e Gingras, 1990), que Gonzalez (1992) traduziu e adaptou para a Espanha e cujo uso no Brasil foi possibilitado pela adaptação de Balbinotti e Tétreau (2002), que asseguraram as qualidades psicométricas para esse uso. No mais, o Inventário de Desenvolvimento Profissional (IDP), cujas qualidades psicométricas foram demonstradas por Dupont e Marceau (1982), com a ajuda de dados colhidos pela aplicação desse instrumento em estudantes do ensino médio canadenses, de ambos os sexos, mede claramente as dimensões correlatas ao conceito de maturidade vocacional de Donald Super. Uma versão brasileira deste último foi assegurada por Lobato (2001).

\section{QUESTÃo CENTRAL DESTA PESQUISA}

Partindo-se dos conteúdos teóricos e empíricos apresentados anteriormente, foi possível formular a seguinte questão central desta pesquisa: "Existem diferenças significativas $(p<0,05)$ em escores obtidos nos níveis de maturidade vocacional, nos adolescentes investigados, segundo o sexo, a idade, o ano de instrução no ensino médio e, finalmente, o tipo de escola (se pública ou privada)?" Para adequadamente responder a ela foram empregados procedimentos metodológicos, éticos e estatísticos. Estes procedimentos serão apresentados a seguir.

\section{MÉTODO}

\section{Procedimentos, sujeitos e instrumentos}

Após contatar os conselheiros de orientação ou psicólogos das escolas escolhidas, todos os alunos eram convidados a participar, mas sublinhava-se que eles eram livres para participar ou não, ou para desistir da pesquisa a qualquer momento, caso viessem a desejálo. Com a concordância verbalmente expressa, pedia-se que os jovens (os de 18 anos) ou o(a) professor(a) assinassem o consentimento informado (livre e esclarecido). Ainda, considerando-se que não era exigida a identificação nominal dos participantes, os estudantes estavam assegurados da confidencialidade de suas respostas.

A escolha da amostra foi por conveniência (não aleatória), mas com o cuidado de evitar grupos de classes especiais. Os 860 estudantes - de ambos os sexos e com idades variando de 14 a 18 anos, do ensino médio, das redes pública e privada de ensino implicados nesta pesquisa estavam regularmente inscritos no ensino médio e foram recrutados em 3 escolas da capital e 5 escolas de duas cidades do
Interior do Estado do Rio Grande do Sul. A pedido formal dos responsáveis pelas escolas, os nomes das instituições de ensino não serão mencionados.

A fim de melhor caracterizar o plano sociocultural das escolas pesquisadas, é conveniente dizer que as escolas escolhidas estão situadas em 3 grandes centros universitários urbanos gaúchos, localizados no Leste, Centro e Noroeste do Estado. Destarte, os sujeitos que compõem a amostra se originam de diferentes regiões do Estado, podendo, então, ser descritos como pertencentes a diversas nacionalidades de origem. Esta situação, de tipo cosmopolita, provavelmente atenua mas sem eliminar completamente - as possíveis diferenças socioculturais capazes de influenciar sua identificação com seus antepassados e/ou o modelo profissional associado a essas gerações precedentes. Assim, na realidade, não se esperou encontrar diferenças nas respostas do questionário utilizado. De fato, esta diferença não foi objeto de uma verificação empírica neste estudo; entretanto, exploraram-se as possíveis diferenças socioeconômicas segundo os tipos de escola: públicas e privadas.

Foram utilizados dois instrumentos: um questionário sociodemográfico (apenas para controle das variáveis dependentes: sexo, idade, tipo de escola e ano do ensino médio) e o Questionário de Educação à Carreira (QEC-96), um instrumento cujas qualidades psicométricas já foram objeto de verificação em língua portuguesa, no Brasil (Balbinotti, 2001; Balbinotti \& Tétreau, 2002).

Versão brasileira do Questionário de Educação à Carreiral $^{1}$, O QEC-96, de Dupont e Gingras (1990), foi originalmente elaborado como um instrumento de avaliação das necessidades de educação para a carreira de estudantes do último ano de nível médio. As elaboradoras concebem que a educação para a carreira deve levar a um duplo desenvolvimento desses jovens. $\mathrm{O}$ primeiro refere-se a uma significação e valorização do trabalho (é nesse sentido que as autoras construíram uma escala denominada Sentido e Importância do trabalho). O segundo refere-se a uma preparação para a vida profissional (nesse sentido, as autoras construíram uma escala, denominada Preparação à Carreira). Se a primeira escala é unitária (unidimensional), a segunda comporta seis dimensões: etapas efetuadas, fatores considerados, profissão preferida, pesquisa e conservação de emprego, pessoas e fontes consultadas, e atividades realizadas. Às duas escalas afetivas as autoras acrescentam uma terceira,

1 Informações sobre o instrumento podem ser requeridas por e-mail mbalbinotti@ videotron.ca aos autores deste estudo. 
cognitiva, denominada Conhecimentos do Mundo do Trabalho. Sabe-se, entretanto, que essa terceira escala, por um lado, supõe um nível de conhecimento próprio dos estudantes do último ano do ensino médio do Quebec (Canadá), e por outro, leva em conta que as qualidades psicométricas das medidas afetivas do desenvolvimento de carreira são mais consistentes e estáveis que as medidas cognitivas. Sendo assim, reterse-ão, nesse estudo, apenas as duas escalas afetivas, conforme fora indicado por Coallier, Diop e Dupont (1995) e por Dupont, Gingras e Marceau (1992).

Assim, as duas escalas afetivas do QEC comportam 96 enunciados, repartidos em duas escalas, integrando sete dimensões. A primeira escala - sentido e importância do trabalho (22 itens) - visa identificar as crenças dos jovens, basicamente aquelas relativas à significação e à importância que eles atribuem ao trabalho e aos trabalhadores. A segunda escala preparação para a carreira - tem por objetivo avaliar suas atitudes de planificação e de exploração relativas às tarefas de desenvolvimento de carreira. Esta última é dividida em seis dimensões. As quatro primeiras referem-se: às tarefas de planificação - ou seja, às etapas efetuadas (13 itens) para fazer suas escolhas escolares e profissionais; aos fatores considerados (17 itens) para efetuar suas escolhas de carreira; à profissão preferida (9 itens) ou o tipo de profissão ou de emprego que lhe interessa; e, finalmente, às competências que o jovem acredita possuir em matéria de pesquisa e conservação de emprego (11 itens), tanto no nível dos métodos quanto no das técnicas para procurar, encontrar, obter e conservar o emprego. As duas últimas dimensões concernem às tarefas de exploração, isto é, às informações que ele obtém através de pessoas e fontes de consulta (11 itens) e por meio das atividades realizadas (13 itens) por ele mesmo. Para medir as atitudes do sujeito em relação a essas diferentes dimensões de sua preparação para a vida profissional, utiliza-se uma escala de tipo Likert (Likert, 1932), graduada em 5 pontos, indo de "completamente em desacordo" a "completamente de acordo", segundo as dimensões em estudo.

\section{RESULTADOS, INTERPRETAÇÕES E DISCUSSÕES}

Para responder adequadamente à questão central desta pesquisa, procedeu-se à exploração dos escores obtidos através da QEC, segundo princípios norteadores comumente aceitos na literatura especializada (Angers, 1992; Bisquera, 1987; Bryman \& Cramer, 1999; Dassa, 1999; Pestana \& Gageiro,
2003; Reis, 2000; Sirkin, 1999; Trudel \& Antonius, 1991; Vallerand, 1989). Caminho feito, apresentam-se, sucessiva e sistematicamente, os resultados das análises de itens, das estatísticas descritivas e das comparações de médias conforme a variável controlada (sexo, idade, tipo de escola e ano do ensino médio). Destaque-se que a apresentação formal da "análise de itens", neste estudo, tem por objetivo demonstrar a confiabilidade dos valores das médias encontradas, pois estas, por poderem ser enviesadas pela presença de casos extremos, poderiam não ser representativas dos comportamentos inventariados.

\section{Análise de itens}

Destaque-se que as médias encontradas para cada um dos 96 itens estudados individualmente variaram entre 1,71 e 3,33, com desvios-padrão associados variando entre 0,45 e 1,07. Esses resultados preliminares são considerados satisfatórios, pois não houve aderência predominante (seja positiva seja negativa) a nenhum dos itens isolados, ou seja, itens com médias muito próximas aos valores extremos (1 ou 5). Destaque-se ainda que a variabilidade dos resultados encontra-se classificada de restrita a moderada, indicando certa homogeneidade na dispersão avaliada. Já a média encontrada para o instrumento total foi de 257,23, com um desvio-padrão associado de 29,59. Como o intervalo total esperado era de 96 a 384 pontos (com média esperada de 240 pontos) e o observado foi de 150 a 354 (com um intervalo interquartil de 37 pontos), observam-se valores próximos entre a média esperada e a observada. Conquanto a mediana das correlações item-total tenha sido substancialmente elevada $(r=0,52), 7$ questões (das 96) revelaram valores inferiores a 0,20. Estes últimos dados poderiam indicar certa necessidade de revisão das qualidades métricas destes itens, quando considerados isoladamente; entretanto, comparando os índices Alpha - que variaram de 0,932 a 0,935, para os itens retirados - com o coeficiente Alpha para a escala total sem a exclusão de nenhum item (0,934), verificamos que esse procedimento se torna desnecessário e improdutivo, podendo ainda causar perda na validade de conteúdo, principalmente quanto à pertinência e à adequada exploração de todas as arestas - significados - do conceito. Finalmente, mesmo considerando-se o elevado número de itens (Dassa, 1999), o valor Alpha encontrado para a escala total $(0,934)$ revela um escore elevado da consistência interna do instrumento para estes dados, um importante preditor da confiabilidade e precisão dos resultados. 


\section{Estatísticas descritivas gerais}

Como se pode observar na Tabela 2, os índices obtidos nas médias de maturidade vocacional, independentemente da variável controlada, variaram, em valores nominais, relativamente pouco (253,3 a 262,9). O desvio-padrão seguiu nesta mesma ordem, variando de 25,9 a 35,2. Com o objetivo de verificar a adequação do uso de testes paramétricos para a comparação destas médias e com base nos resultados dos desvios, a igualdade estatística das variâncias foi testada, comprovada e assumida com a ajuda do cálculo $F$ de Levène para as variáveis: $\operatorname{sexo}\left(F_{(1,858)}=0,613 ; p\right.$ $=0,434)$, idade $\left(F_{(4,855)}=1,614 ; p=0,085\right)$ e ano do ensino médio $\left(F_{(2,854)}=2,409 ; p=0,090\right)$. De maneira geral, esses resultados são excelentes indicadores para o uso de instrumentais paramétricos de comparação das médias. A única exceção encontrada diz respeito à variável tipo de escola $\left(\mathrm{F}_{(1,858)}=17,173 ; p<0,001\right)$. Esse resultado pode tornar complexa a análise paramétrica desses dados. Sendo assim, para não ficar dúvida quanto à pertinência no uso de instrumentais paramétricos, foram pormenorizadamente testados os índices de normalidade pelo cálculo KolmogorovSmirnov $(p>0,05), \quad$ a assimetria ($1,96<$ Skewness $\left./ E P_{s}<1,96\right)$ e 0 achatamento ($1,96<$ Kurtosis/EP $\left.P_{k}<1,96\right)$. Sem exce-ções (Tabela 2), estes resultados indicaram tratar-se de dados com aderência à normalidade, portanto aptos para o uso dos instrumentais desejados.

Tabela 2. Cálculos de Tendência Central, Dispersão e Distribuição por Variáveis em Estudo

\begin{tabular}{|c|c|c|c|c|c|c|c|c|c|c|}
\hline \multirow{3}{*}{\multicolumn{2}{|c|}{ Variáveis }} & \multicolumn{5}{|c|}{ Tendência central e dispersão } & \multicolumn{4}{|c|}{ Distribuição } \\
\hline & & \multirow{2}{*}{ Média } & \multirow{2}{*}{ D.P. } & \multirow{2}{*}{ Min } & \multirow{2}{*}{$\operatorname{Max}$} & \multirow{2}{*}{$\begin{array}{l}\text { Inter- } \\
\text { quartil }\end{array}$} & \multicolumn{2}{|c|}{ Normalidade } & \multirow{2}{*}{ Assimetria } & \multirow{2}{*}{ Achatamento } \\
\hline & & & & & & & $\mathbf{K}-\mathbf{S}^{\mathbf{a}}$ & Sig. & & \\
\hline \multirow{2}{*}{ Sexo } & M & 254,1 & 29,7 & 150 & 336 & 40 & 0,028 & $0,200^{\mathrm{b}}$ & $0,72^{\mathrm{c}}$ & $0,43^{\mathrm{d}}$ \\
\hline & $\mathrm{F}$ & 259,8 & 29,3 & 174 & 354 & 35 & 0,040 & 0,106 & $0,62^{\mathrm{c}}$ & $1,52^{\mathrm{d}}$ \\
\hline \multirow{5}{*}{ Idade } & 14 & 262,9 & 32,8 & 191 & 325 & 40 & 0,145 & $0,200^{\mathrm{b}}$ & $0,21^{\mathrm{c}}$ & $0,29^{\mathrm{d}}$ \\
\hline & 15 & 253,3 & 29,9 & 168 & 345 & 32 & 0,067 & 0,069 & $0,91^{\mathrm{c}}$ & $1,40^{\mathrm{d}}$ \\
\hline & 16 & 257,9 & 27,5 & 186 & 354 & 33 & 0,036 & $0,200^{\mathrm{b}}$ & $0,31^{\mathrm{c}}$ & $0,32^{\mathrm{d}}$ \\
\hline & 17 & 260,1 & 30,1 & 172 & 340 & 37 & 0,052 & 0,086 & $0,63^{\mathrm{c}}$ & $1,19^{\mathrm{d}}$ \\
\hline & 18 & 254,1 & 34,6 & 150 & 325 & 52 & 0,068 & $0,200^{\mathrm{b}}$ & $1,03^{\mathrm{c}}$ & $0,48^{\mathrm{d}}$ \\
\hline \multirow{2}{*}{ Escola } & Privada & 253,9 & 25,9 & 168 & 332 & 34 & 0,030 & $0,200^{\mathrm{b}}$ & $1,82^{\mathrm{c}}$ & $0,19^{\mathrm{d}}$ \\
\hline & Pública & 260,6 & 32,5 & 150 & 354 & 42 & 0,028 & $0,200^{\mathrm{b}}$ & $0,10^{\mathrm{c}}$ & $0,51^{\mathrm{d}}$ \\
\hline \multirow{3}{*}{$\begin{array}{l}\text { Ano do ensino } \\
\text { médio }\end{array}$} & $1^{\mathrm{o}}$ & 259,1 & 35,2 & 150 & 354 & 37 & 0,081 & 0,054 & $0,98^{\mathrm{c}}$ & $0,82^{\mathrm{d}}$ \\
\hline & $2^{\circ}$ & 253,7 & 28,8 & 168 & 345 & 39 & 0,033 & $0,200^{\mathrm{b}}$ & $0,32^{\mathrm{c}}$ & $0,61^{\mathrm{d}}$ \\
\hline & $3^{\circ}$ & 260,2 & 28,1 & 179 & 336 & 37 & 0,034 & $0,200^{\mathrm{b}}$ & $0,25^{\mathrm{c}}$ & $0,56^{\mathrm{d}}$ \\
\hline
\end{tabular}

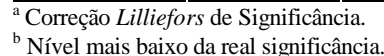

${ }^{\mathrm{c}}$ Simetria aceita para valores entre $-1,96 \mathrm{e}+1,96$.

${ }^{\mathrm{d}}$ Curva mesocúrtica aceita para valores entre $-1,96$ e $+1,96$

Dos valores referentes às estatísticas de dispersão (ver Tabela 2), nota-se apenas relativa homogeneidade quanto aos valores mínimos e máximos obtidos nas variáveis controladas. No que se refere aos valores máximos, destaca-se a menor variabilidade observada, de 325 a 354 pontos, o que surpreende, pois os índices totais de maturidade vocacional são elevados. Sabe-se, entretanto, que se pode chegar até 384 pontos, considerando-se a escala em questão. Esta variabilidade encontrada (29 pontos), independentemente da variável em estudo, pode ser compreendida como de certa homogeneidade nos casos extremos, à direita da curva. Pode-se interpretar esse fenômeno sugerindo que o sexo, a idade, o tipo de escola e o ano do ensino médio não predizem nem impulsionam, de forma unitária, um comportamento de aquiescência positiva. Futuras ocorrências de casos aberrantes extremos à direita da curva poderiam ser interpretadas apenas por diferenças individuais (que, logicamente, podem ocorrer), mas não associadas ao sexo ou a qualquer outra das variáveis controladas. Já no que se refere aos valores mínimos, denota-se que a variabilidade é maior (de 150 a 191 pontos), o que representa um intervalo de 41 pontos. Isso surpreende, pois índices menores sugerem variabilidades menores; logo, requer-se uma análise pormenorizada. No caso das variáveis sexo, tipo de escola e ano do ensino médio, nota-se ainda certa homogeneidade no limite mínimo, o que pode ser encarado como esperado. Já no caso da variável idade, essa observação não se aplica totalmente. Parece que alguns jovens de 18 anos se apresentam mais críticos e precisos quanto às suas respostas ao QEC. Isso pode ser mais claramente notado quando observados os valores mínimos encontrados nos jovens de 14 anos. Estes últimos parecem ser menos cautelosos na expressão de suas atitudes e comportamentos ante as questões de maturidade vocacional. Simbolicamente, esses 
resultados poderiam ser representados por um "W" com pernas menores à sua direita. Imaginando-se esta forma, fica mais fácil de aceitar uma possível idéia cíclica do desenvolvimento da maturidade vocacional, ao mesmo tempo em que ocorre certa tendência a precisar, objetivamente melhor, que atividades fazer e que atividades não fazer, com o intuito de responder às tarefas de desenvolvimento com as quais o jovem é confrontado.

\section{Comparações de médias}

Quanto à variável sexo, um teste t para amostras independentes foi conduzido e seus resultados $\left(\mathrm{t}_{(858)}=\right.$ $2,782 ; \quad p=0,006)$ indicaram existirem diferenças altamente significativas $(p<0,01)$ entre os níveis de maturidade vocacional dos adolescentes e os das adolescentes. Na realidade, é muito difícil explicar, objetivamente, por que as adolescentes apresentam médias maiores nos índices de maturidade vocacional do que $o s$ adolescentes. De certa forma, esse resultado vem ao encontro do consenso da sociedade em aceitar que as meninas maturam mais cedo que os meninos, quase independentemente dos compor-tamentos humanos ligados à personalidade aos quais se associa o termo maturidade (social, emocional, sexual, intelectual, afetivo, etc.). Parece que, de alguma forma, a criação dos filhos, na sociedade gaúcha (e, quem sabe, na sociedade ocidental), estimula certos comportamentos que são típicos das adolescentes e outros que são típicos dos adolescentes. Já que os comportamentos preditores da maturidade vocacional não foram explorados neste estudo, a melhor explicação até o momento seria aquela de caráter cultural ou regional. Não obstante, estudos precisos devem ser conduzidos para que uma melhor explicação desse fenômeno venha à luz do dia!

Quanto à variável idade, realizou-se a estatística ANOVA One-Way, e seus resultados $\left(F_{(4,855)}=1,740\right.$; $p=0,139)$ indicaram não existir nenhuma diferença significativa $(p>0,05)$ entre as idades em estudo. Tal resultado apresenta implicações favoráveis e desfavoráveis à teoria. No que se refere àquelas de caráter favorável, pode-se interpretar que nesse curto período do ciclo vital humano (14 a 18 anos) os adolescentes apresentam, em geral, os mesmos índices nas mesmas questões, resultando em níveis de maturidade vocacional semelhantes, do ponto de vista estatístico. Teoricamente, estes jovens se encontram, fundamentalmente, nas tarefas de desenvolvimento cristalização de uma preferência profissional e planificação de uma carreira (duas das tarefas básicas do desenvolvimento do comportamento maduro). De maneira geral, eles ainda não saíram para efetivamente explorar o mercado de trabalho, enfrentando dificuldades que os levariam a ter que utilizar seus reais recursos atitudinais e cognitivos. Quanto ao caráter desfavorável, poder-se-ia esperar que os níveis de maturidade vocacional efetivamente variassem, mesmo que não de forma linear, mas cíclica, elevandose significativamente de acordo com o avanço da idade. Entretanto, isso não se aplica à faixa etária estudada, ao menos na amostra em questão. Pode ser que exista um aumento significativo na maturidade vocacional quando os jovens efetivamente trabalharem, explorando suas reais capacidades, habilidades, aptidões, valores e interesses, saindo da simples manifestação afetiva e entrando, de fato, no mundo profissional. De acordo com as médias apresentadas na Tabela 2, podem-se apenas testemunhar índices nominais, crescentes e lineares (mas não significativos) de maturidade vocacional entre as idades de 15, 16 e 17 anos. No caso dos 18 anos, nota-se uma nova queda nos índices, os quais se aproximam àqueles obtidos aos 15 anos. No caso dos 14 anos, observa-se que os mais jovens aderem melhor às possibilidades de respostas mais positivas. Isso pode deixar entender que estes últimos respondam mais positivamente por uma relativa (e, talvez, pouco madura) falta de critérios de resposta mais consistentes, estáveis e diferenciados. Mais uma vez, vale a pena desenvolver estudos para verificar essas importantes hipóteses interpretativas levantadas.

Quanto à variável tipo de escola (se pública ou privada), um teste $\mathrm{t}$ para amostras independentes foi conduzido e seus resultados $\left(t_{(858)}=3,479 ; p=0,001\right)$ indicam existir diferença altamente significativa $(p<0,01)$ entre as respostas dos adolescentes de escolas privadas e as daqueles de escolas públicas. Analisando-se os valores de média apresentados na Tabela 2, denota-se que a diferença é favorável aos estudantes de escolas públicas. Uma tentativa de explicação desse fenômeno poderia ser a necessidade de maturação vocacional prematura por parte dos estudantes da rede pública. Talvez, neste caso, interfira um fator de ordem financeira (entre outros possíveis). Este fato pode sugerir que os estudantes da rede pública necessitam, de fato, entrar no mundo do trabalho antes dos seus pares da rede privada de ensino médio. Por si só, esse aspecto não teria muito significado, mas considerando-se as colocações de Balbinotti, Marocco e Tétreau (2003) quanto à cristalização na indecisão, esta interpretação torna-se mais viável e adequadamente aceitável. Assim, se um adolescente experimenta dificuldades em completar, 
com sucesso, o desenvolvimento de sua maturidade vocacional, ele poderá, por um lado, ver-se confuso e indeciso em face de sua futura orientação (Balbinotti, 2001; Gordon, 1984; Marocco, 1991; Tittley \& Tittley, 1980) e, por outro, sentir-se forçado (por problemas de ordem financeira, por exemplo) a aceitar as oportunidades que aparecem, sem uma maior e/ou mais adequada reflexão quanto a seus gostos, preferências e valores no mundo do trabalho. Isso poderia acarretar certa "maturidade vocacional prematura", pois tal jovem não percorreria as tarefas de desenvolvimento, estados e subestados que caracterizam um comportamento vocacional maduro. É claro que esta "necessidade de trabalhar" que os jovens das escolas públicas experimentam mais frequientemente que seus pares da rede privada, não seria a única justificativa para esta diferença; pode ser que toda a vida desses jovens já os leve ao amadurecimento precoce! Mas esta hipótese necessita ser testada ulteriormente, com um design de pesquisa apropriado.

Quanto à variável ano do ensino médio (primeiro, segundo e terceiro), a estatística ANOVA One-Way foi realizada e seus resultados $\left(F_{(2,854)}=4,878 ; p=0,008\right)$ indicaram existir ao menos uma diferença altamente significativa $(p<0,01)$ nos índices de maturidade vocacional entre os três anos em estudo. Tal resultado é um pouco surpreendente, pois, segundo o senso comum, pode-se imaginar que, se não houve diferenças entre as idades, pouco se esperaria encontrar na variável ano do ensino médio. Testes complementares (Teste Complementar de Bonferroni, considerando que as variâncias são homogêneas) foram conduzidos a fim de poder-se encontrar em quais pares de médias ocorrem diferenças significativas $(p<0,05)$. Apenas uma diferença significativa foi encontrada $\left(D_{i f}=6,46\right.$; $p=0,008)$ : ocorreu entre as resultados do $2^{\circ}$ e $3^{\circ}$ anos do ensino médio. Parece que, na iminência de uma decisão (no terceiro ano do ensino médio), os jovens mostram índices mais elevados de maturidade vocacional, ou seja, apresentam-se com melhor condição para enfrentar as tarefas de desenvolvimento vocacional do que seus pares do ano intermediário do ensino médio. Curioso foi, entretanto, que os adolescentes do $1^{\circ}$ ano do ensino médio apresentaram média (ainda que inferior) nominalmente muito próxima àquela de seus pares terceiranistas. Interpretase esse fenômeno seguindo a mesma linha da variável idade: deixa entender que os mais novos - portanto, inscritos no início do ensino médio - respondem mais positivamente por uma relativa (e, quem sabe, pouco madura!) falta de critérios de resposta mais consistentes, estáveis e diferenciados. $\mathrm{Na}$ realidade, não se percebe aumento linear nos índices médios de maturidade vocacional (ver Tabela 2). Tais resultados podem ser simbolicamente expressos com uma letra "V" - altos resultados no primeiro ano, baixos resultados no segundo ano e novamente altos resultados no terceiro ano. Entretanto, ao analisar os desviospadrão, nota-se que os índices de variabilidade de resposta vão diminuindo, dando credibilidade à interpretação de que as respostas são mais consistentes, estáveis e diferenciadas apenas no terceiro ano do ensino médio. Esse dado pode ser de grande importância, ao levar-se em conta que, na realidade, existe uma diminuição nominal nos desvios-padrão associada às médias desta variável. Sendo assim, não se pode afirmar categoricamente, nem para os dados em questão, que o fato de pertencer ao primeiro ano do ensino médio facilitaria uma resposta mais positiva aos itens de maturidade vocacional apresentados, mas, sem dúvida, ocorreu uma diferença, com crescimento linear nos valores. É claro que, considerando-se a semelhança estatística dos dados $(p>0,05)$, a melhor interpretação seria a análise de casos isolados. Isso nos leva a imaginar a possibilidade de existirem, concretamente, jovens que apresentam diferentes níveis de maturidade vocacional (podendo ser altos, médios ou baixos), independentemente do ano do ensino médio em que se encontrem.

\section{CONCLUSÕES, LIMITAÇÕES E PERSPECTIVAS PARA NOVOS ESTUDOS}

Este trabalho permitiu explorar diferenças e semelhanças estatísticas encontradas nas respostas de 860 adolescentes de ambos os sexos, com idades variando de 14 a 18 anos, oriundos de oito escolas, públicas e privadas, de três localidades do Estado do Rio Grande do Sul. A partir dos cuidados procedurais, éticos e metodológicos, os resultados indicam diferenças significativas $(p<0,05)$ nas respostas dos adolescentes quando controladas as variáveis sexo, tipo de escola (se pública ou privada) e ano de instrução no ensino médio. Mesmo não sendo possível generalizar os resultados obtidos nesta pesquisa (o procedimento de coleta amostral foi não-aleatório), tanto o número de sujeitos em estudo quanto a pluralidade setorial onde foram coletadas as respostas dos sujeitos permitem, ao menos, conclusões hipotéticas importantes. Mesmo em se considerando 
esta limitação de caráter amostral, pode-se concluir que as adolescentes deste estudo, independentemente do tipo de escola, idade e ano do ensino médio, apresentaram maior maturidade vocacional inventariada que os adolescentes. Do mesmo modo, os adolescentes do ensino público, independentemente do sexo, da idade e do ano do ensino médio, apresentam maior maturidade vocacional que seus pares do ensino privado. Finalmente, os ultimanistas (independentemente do sexo, da idade e do tipo de escola) apresentam maiores índices de maturidade vocacional que seus pares do segundo ano do ensino médio.

Cabe finalizar este estudo indicando que estes resultados podem ser particularmente úteis para orientadores vocacionais e psicólogos escolares, notadamente àqueles profissionais que orientam, mais especificamente, alunos do ensino médio (de 14 a 18 anos) e se interessam em explorar sua maturidade vocacional. Então, elementos como habilidades (por exemplo, aquelas associadas à capacidade do jovem para encontrar e conservar um emprego), conhecimentos (fundamentalmente aqueles associados ao mundo do trabalho) e atitudes (ligadas ao pensamento e ação, como interesse e iniciativa, entre outras), ao menos aqueles que foram avaliados a partir da Versão Brasileira do Questionário de Educação à Carreira, parecem ser uma fonte importante de informação para esses profissionais, permitindo que eles entendam melhor como esses elementos se integram na dinâmica geral da personalidade vocacional dos jovens. Destaca-se que estes profissionais devem considerar as diferenças estatisticamente significativas aqui apresentadas e criar modelos de orientação e de educação para a carreira que sejam adequados aos grupos específicos estudados. Medidas de maturidade vocacional são particularmente interessantes quando utilizadas dentro de um contexto maior, ou seja, quando esses profissionais se interessam em ajudar o jovem na preparação de sua vida profissional futura.

Novos estudos devem ser conduzidos a fim de se verificar a existência de diferenças estatísticas nos níveis de maturidade vocacional, mas controlando mais do que uma variável em conjunto (metodologias multivariadas de análise), por exemplo, meninas de 14 anos em relação a meninos de 14 anos, com controle pelo tipo de escola e ano do ensino médio. Assim, acredita-se poder melhor explicar os fenômenos relativos a esse importante aspecto da personalidade humana e de seu desenvolvimento profissional. Acredita-se, ainda, que este período de vida é fundamental e determinante de outros, no ciclo vital humano. Assim, sugere-se a realização de estudos com um intervalo maior de idades, abarcando, inclusive, outras variáveis dependentes importantes (cidades capital e interior -, escolas urbanas, semi-rurais e rurais, entre outras) bem como a inclusão de outras etapas (fases) do desenvolvimento profissional humano.

\section{REFERÊNCIAS}

Angers, M. (1992). Initiation pratique à la méthodologie des sciences humaines. Montréal: Les Éditions de la Chenelière.

Balbinotti, M. A. A. (2001). Vers un modèle explicatif de la cristallisation des préférences professionnelles durant l'adolescence. Tese de Doutorado Não-Publicada, Faculté des Arts et des Sciences, Universidade de Montreal, Montreal.

Balbinotti, M. A. A. (2003). A Noção Transcultural de Maturidade Vocacional na Teoria de Donald Super. Psicologia Reflexão e Crítica, 16(3), 461-473.

Balbinotti, M. A. A. \& Tétreau, B. (2002). L'Éducation à la Carrière: Une Étude Brésilienne de la Validité Transculturelle du Questionnaire sur l'Éducation à la Carrière. International Journal for Educational and Vocational Guidance, 2(2), 101-114.

Balbinotti, M. A. A., Marocco, A. \& Tétreau, B. (2003). Verificação de propriedades psicométricas do Inventário de cristalização das preferências profissionais. Revista Brasileira de Orientação Profissional, 4(1), 71-86.

Bisquera, R. (1987). Introducción a la estadística aplicada a la investigación educativa: Un enfoque informático con los paquetes BMDP y SPSS. Barcelona: PPU.

Bryman, A. \& Cramer, D. (1999). Quantitative data analysis with SPSS release 8 for Windows: A guide for social scientists. New York: Routledge.

Coallier, J. C., Diop, M. \& Dupont, P. (1995). Étude interculturelle de besoins d'éducation à la carrière chez des jeunes du secondaire. En Corporation Canadienne de Psychologie (Org.), Actes $d u 21^{e}$ colloque national touchant le développement de carrière (pp. 131-139). Toronto: Presses Univesitaire de Toronto.

Crites, J. O. (1978). Career maturity inventory. Monterey: McGraw-Hill.

Dassa, C. (1999). Analyse multidimensionnelle exploratoire et confirmative. Montreal: Université Montréal.

Dupont, P. \& Gingras, M. (1990). Questionnaire sur l'éducation à la carrière. Sherbrooke: Presses Universitaires de Sherbrooke.

Dupont, P. \& Marceau, D (1982). Manuel de l'Invetaire de dévelppement professionnel: adaptation et normalisation. Sherbrooke : Presses Universitaires de Sherbrooke.

Dupont, P., Gingras, M. \& Marceau, D. (1992). L'entrée sur le marché du travail des finissants du secondaire général : Une analyse de leurs besoins d'éducation à la carrière. Revue canadieenne de counseling, 26(4), 256-268. 
Forrest, D. J. \& Thompson, A. S. (1974). The career development inventory. In D. E. Super (Ed.), Measuring Vocational Maturity for Counseling and Evaluation (pp. 53-66). Washington: National Vocational Guidance Association.

Gonzalez, M. P. (1992). Les intervenciones educativas para el desarrollo de la carrera: Análisis de las necesidades de desarrollo para la carrera de los estudiantes al finalizar la educación secundaria. Tese de Doutorado NãoPublicada, Programa de Pós-Graduação em Psicologia, Faculdade de Psicologia, Universidade de Oviedo, Espanha.

Gordon, V. N. (1984). The Undecided College Student: An Academic and Career Advising Challenge. Springfield: Charles C. Thomas.

Holland, J. L. (1959). A theory of vocational choice. Journal of Counseling Psychology, 6(1), 35-45.

Holland, J.L. (1997). Making vocational choices: A theory of vocational personalities and work environments. Odessa, FL: Psychological Assessment Resources.

Likert, R. A. (1932). Technique for the measurement of attitudes. Archives of Psychology, 22(140), 44-53.

Lobato, C. R. P. S. (2001). Maturidade vocacional e gênero: adaptação e uso de instrumentos de avaliação. Dissertação de Mestrado Não-Publicada, Programa de PósGraduação em Psicologia do Desenvolvimento, Universidade Federal do Rio Grande do Sul, Porto Alegre.

Marocco, A. (1991). L'influence du test visuel d'intérêts et as version verbale sur la cristallisation des projets professionnels durant l'adolescence. Thèse de Doctorat Non-Publieé, Faculté d'Arts et Sciences, Universidade de Montreal, Montreal.

Parsons, F. (1909). Choosing a vocation. Boston: Houghton Mifflin.

Pestana, M. H. \& Gageiro, J. G. (2003). Análise de dados para ciências sociais: a complementaridade do SPSS. Lisboa: Edições Sílabo.

Reis, E. (2000). Estatística descritiva. Lisboa: Edições Sílabo.

Sirkin, R. M. (1999). Statistics for the Social Sciences. London: Sage Publications.

Super, D. E. (1953). A theory of vocational development. American Psychologist, 8(1), 185-190.

Super, D. E. (1955). The dimensions and measurement of vocational maturity. Teachers College Record, 57(1), 151163.

Super, D. E. (1957). The psychology of careers. New York: Harper Collins.

Super, D. E. (1963a). Vocational development in adolescence and early adulthood: Tasks and behavior. In D. E. Super
(Ed.), Career development: Self concept theory (pp. 1-16). New York: College Entrance Examination Board.

Super, D. E. (1963b). Toward making self-concept theory operational. In D. E. Super (Ed.), Career development: Self concept theory (pp. 17-32). New York: College Entrance Examination Board.

Super, D. E. (1972). Vocational development theory in twenty years. In J. M. Whiteley \& A. Resnikoff (Eds.), Perspectives on vocational development. Washington: American Personnel and Guidance Association.

Super, D. E. (1980). A life-time, life-space, approach to career development. Journal of Vocational Behavior, 13(2), 282298.

Super, D. E. (1985a). Exploration des frontières du développement vocationnel. Connat, 8(2), 271-297.

Super, D. E. (1985b). Coming of age in Middletown: careers in the making. American Psychologist, 40(4), 405-415.

Super, D. E. (1990). The life-span, life-space approach to career development. In D. Brown \& L. Brooks (Eds.), Career choice and development (pp. 197-261). San Francisco: Jossey-Bass.

Super, D. E., Savickas, M. L. \& Super, C. M. (1996). The lifespan, life-space approach to careers. In D. Brown \& L. Brooks (Eds.), Career choice and development (pp. 121178). San Francisco: Jossey-Bass.

Super, D. E., Sverko, B. \& Super, C. M. (1995). Life roles, values and careers: International findings of the work importance study. San Francisco: Jossey-Bass.

Super, D. E., Thompson, A. S. \& Lindeman, R. H. (1988). Adult Concerns Inventory: Manual for research and exploratory use in counseling. Palo Alto: Consulting Psychologists.

Tittley, R. W. \& Tittley, B. S. (1980). Initial choice of college major: Are only the "undecided" undecided? Journal of College Student Personnel, 21(2), 293-298.

Trudel, R. \& Antonius, R. (1991). Méthodes quantitatives apliques aux sciences humaines. Montreal: Les Éditions de la Cheneliére.

Vallerand, R. J. (1989). Vers une métodologie de validation transculturelle des questionnaires psychologiques: Implications pour la recherche en langue française. Psychologie Canadienne, 30(4), 662-680.

Recebido em 09/05/2005 Aceito em 09/08/2006

Endereço para correspondência: Marcos A. A. Balbinotti, 7 de l'Artiste, Kirkland (Qc), H9J 4B6, Canadá. E-mail:mbalbinotti@videotron.ca 